\title{
SPATIAL-TEMPORAL DYNAMICS OF URBAN FIRE INCIDENTS: A CASE STUDY OF NANJING, CHINA
}

\author{
J. YAO ${ }^{\mathrm{a} *}, \mathrm{X}$. Zhang ${ }^{\mathrm{b}}$ \\ ${ }^{\text {a } U r b a n ~ B i g ~ D a t a ~ C e n t r e, ~ U n i v e r s i t y ~ o f ~ G l a s g o w, ~} 7$ Lilybank Gardens, Glasgow, G12 8RZ UK - Jing.Yao@ glasgow.ac.uk \\ ${ }^{b}$ Dept. of Geographical Information Science, Hohai University, 1 Xikang Road, Nanjing, 210098, China - xiaoxiang@ @hu.edu.cn
}

Commission II, WG II/1

KEY WORDS: Urban Fire, ESDA, Spatial-temporal Analyses

\begin{abstract}
:
Fire and rescue service is one of the fundamental public services provided by government in order to protect people, properties and environment from fires and other disasters, and thus promote a safer living environment. Well understanding spatial-temporal dynamics of fire incidents can offer insights for potential determinants of various fire events and enable better fire risk estimation, assisting future allocation of prevention resources and strategic planning of mitigation programs. Using a 12-year (2002-2013) dataset containing the urban fire events in Nanjing, China, this research explores the spatial-temporal dynamics of urban fire incidents. A range of exploratory spatial data analysis (ESDA) approaches and tools, such as spatial kernel density and co-maps, are employed to examine the spatial, temporal and spatial-temporal variations of the fire events. Particular attention has been paid to two types of fire incidents: residential properties and local facilities, due to their relatively higher occurrence frequencies. The results demonstrated that the amount of urban fire has greatly increased in the last decade and spatial-temporal distribution of fire events vary among different incident types, which implies varying impact of potential influencing factors for further investigation.
\end{abstract}

\section{INTRODUCTION}

Fire, either caused by humans or nature, can pose hazard to people, properties and environment, possibly resulting in psychological damage, physical injuries, even death and significant economic losses. For example, there are total about 212,500 fires during 2013-2014 in UK, involving 322 deaths and more than 9,700 non-fatal casualties (DCLG, 2015). According to the National Fire Protection Association of the US, there are 3,240 deaths, 15,925 injuries and $\$ 11.5$ billion economic costs of property damage caused by about 1.24 million fires in total in 2013 (Karter, 2014). As a result, fire and rescue service is of great importance in terms of protecting lives and properties and thus promoting a safer living environment. In order to improve the efficiency and effectiveness of fire safety management, it is essential to well understand spatiotemporal dynamics of fire incidents, which can offer insights for potential determinants of fire events and enables better fire risk estimation, thereby assisting future allocation of prevention resources and strategic planning of mitigation programs.

A lot of research efforts have been devoted to investigating the behaviour, spatial or spatial-temporal patterns, risks and underlying driving factors of wildfire/forest fires (Cova et al., 2005; Yassemi et al., 2008; Gaither et al., 2011). Comparatively, less attention has been paid to urban fires. A few exceptions include recent work by Corcoran et al. (2007a, 2007b, 2011a, 2011b), Asgary et al. (2010) and Špatenková and Virrantaus (2013). Compared to wildfire, urban fire is virtually a both physical and social process (Jennings, 2013), in the sense that it occurs in built environment and affects individuals and socioeconomic activities in the surrounding neighborhood or communities, usually involving both individual causalities and economic losses. Meanwhile, most of the existing work on urban fires has focused on the cases in developed countries, such as the US (Gaither et al., 2011), the UK (Corcoran et al., 2007a, 2007b, 2011a, 2011b; Higgins et al., 2013), Canada (Asgary et al., 2010) and Australia (Corcoran et al., 2011a). So far, few studies have been carried out in developing countries and regions.

The aim of this paper is to explore the spatial-temporal dynamics of urban fires in Nanjing, the capital of Jiangsu Province and also a major city in East China over the last decade. It is well known that China has experienced unprecedented urbanization since 1979 when the reform and opening-up policy started. While tremendous economic growth has been achieved, the extensive urban sprawl has profound influences on both the amount and spatial arrangement of various land-use activities (Deng et al., 2008). One prominent example is that the overall built-up area of major cities in China has expanded by more than $50 \%$ since 2000 , largely for the purpose of economic development (Ren, 2013). Currently more than $50 \%$ of Chinese population lives in cities, with a high proportion of rural-to-urban migrants (NBSC, 2015). Meanwhile, excessively high growth of cities has caused a lot of serious issues, such as air pollution, traffic congestion, highrise and high-density residential districts with little open space. The unbalanced development and unsustainable urban form have greatly increased the risks of disasters in urban areas. For example, recent years have witnessed thousands of fire events in Chinese cities. For example, the residential fire in Shanghai in 2010 caused 58 deaths and 71 injuries (Xinhua News, 2010). Recently, a care home fire in Henan caused 38 deaths of elderly people (BBC News, 26 May, 2015).

\footnotetext{
* Corresponding author
} 
The paper is structured as follows. The next section reviews the relevant work on fire management and services involving geographical information systems (GIS) based spatial analyses. This is followed by an introduction of the research methods, including the study area, the data and the research methods. Then, the results of the spatial-temporal dynamics of fire incidents are presented. The paper concludes with discussion of major findings as well as implications for future strategic planning of fire safety programs.

\section{RELATED WORK}

As fire events occur in geographic space, GIS-based spatial analyses are well suited for the needs of fire and rescue services. On one hand, GIS can provide effective management and process of fire incident data. On the other hand, spatial analyses are powerful tools for exploring spatial/temporal patterns of fire events, identifying potential influencing factors and estimating fire risks. With the increasing availability of high-resolution spatial-temporal data, GIS-based spatial analyses have been widely applied in the analyses of spatial/temporal patterns in fire events, causal relationship between fire events and potential driving factors, and fire behaviour simulation, among others.

First, spatial, temporal, and spatial-temporal patterns of fire events can be explored by a range of spatial analytical approaches. The most straightforward way to depict spatial distribution of fire events is by desktop mapping (Špatenková and Virrantaus, 2013). Besides, more advanced geovisualization techniques can assist unveiling spatial-temporal patterns of fire incidents. For instance, continuous surfaces generated by kernel density estimation (KDE) can reflect spatial variations in fire risks (Corcoran et al., 2007a). Corcoran et al. (2007b) used comaps (Brunsdon, 2001) to explore spatial-temporal patterns of the fire events in South Wales, UK. Similar techniques have also been employed by Asgary et al. (2010) and Corcoran et al. (2011a). Further, coupled with various data collection sensors, web-based GIS platforms can support locating fire service resources and identifying high-risk areas in a real-time manner (Kalabokidis et al., 2013).

Beyond the spatial/temporal distributions of fire incidents, of more interest is often the relationship between the occurrence of fire and the associated drivers. Extensive literature has examined the potential contribution of a set of physical environmental and socioeconomic factors to the fire events (Corcoran et al., 2007a; Yassemi et al., 2008; Corcoran et al., 2011b; Jennings, 2013; Špatenková and Virrantaus, 2013), usually by multiple regression analyses. For instance, it has been found that the frequency of wildfire is closely related to forest fuel, local climate (e.g. temperature and precipitation) and topography (e.g. elevation and aspect) (Yassemi et al., 2008). Regarding urban fires, socioeconomic variables such as population density, building conditions and household level generally have more influence compared to the physical environment (Corcoran et al., 2007a; Corcoran et al., 2011b; Jennings, 2013; Špatenková and Virrantaus, 2013). In addition, Corcoran et al. (2011b) examined the impact of calendar events (e.g. public holidays, school holidays and major sports events) and found that the fire incidents would significantly increase during school holidays.

The identified determinants can be further utilized to predict fire behaviour, particularly the path of wildfire or forest fire, so that timely evacuation of threatened communities and targeting services can be arranged accordingly. For example, several GIS-based cellular automata (CA) models have been developed to simulate the forest fire behaviour (Yassemi et al., 2008). By integrating GIS and fire-spread models, Cova et al. (2005) identified the evacuation trigger points and delineated the trigger buffer with the shortest path algorithm.

As discussed above, GIS-based spatial analyses have been extensively applied in many ways to understand and predict the occurrence of fires, enabling better decision-making for fire and rescue services. This research is to study the fire incidents in a developing country context, seeking the spatial-temporal dynamics over the last decade.

\section{METHODS}

\subsection{Data and Study Area}

The study area of this research is located in the south of Yangtze River within Nanjing, China, covering seven main districts of the city: Xuanwu, Qinhuai, Jianye, Gulou, Yuhuatai, Qixia and Jiangning (Figure 1). The total area is about 598.1 $\mathrm{km}^{2}$ (about $9.1 \%$ of total area of Nanjing), occupied by a total population of 5.06 million (2010) (about $54.4 \%$ of total population of Nanjing).

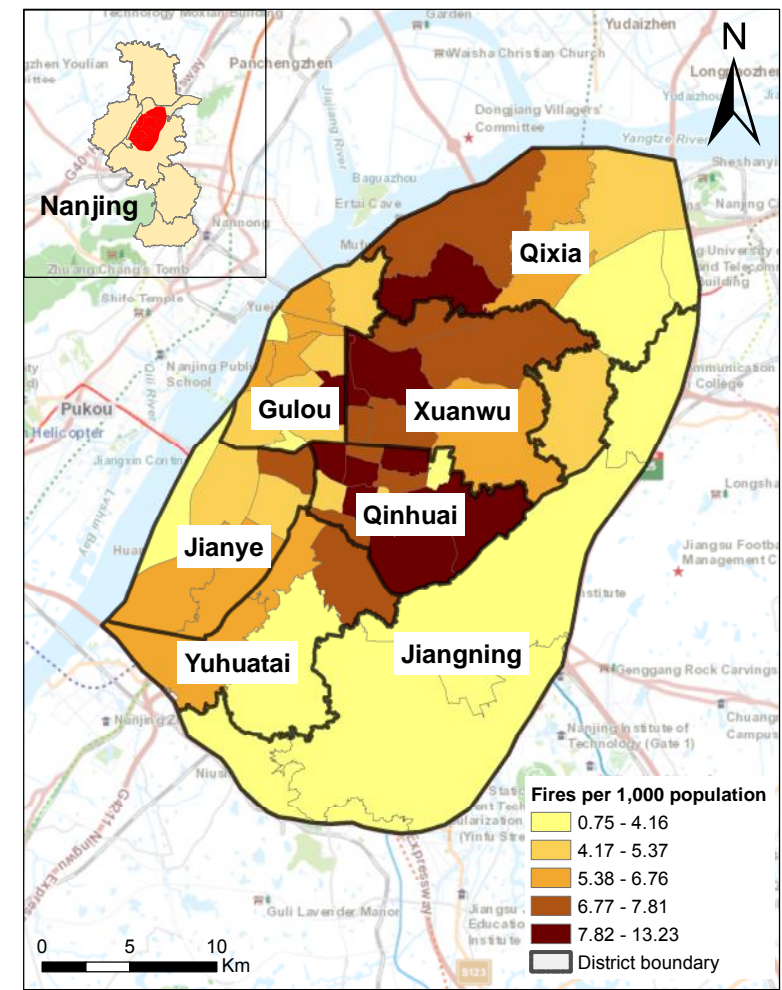

Figure 1. Fire incident rates for Jiedao

Nanjing is the capital of Jiangsu Province and also a city of long history that can be traced back to 495 BCE. Nowadays, Nanjing is an important center of education, commerce, transportation and tourism in East China. Like many other Chinese cities, Nanjing has experienced rapid urbanization in the last three decades with the primary goal of promoting economic growth. An important outcome of fast urban growth is the rapid increase in urban population. For example, the total population in Nanjing has increased about $28.3 \%$ during $2000-$ 2010 (NBSC, 2011), which has resulted in comprehensive 
urban transformation involving both the physical environment and socioeconomic activities. The changes of built environment in relation to urban-social structures as well as the increased population have brought new characteristics to urban fire risks, raising new problems and challenges to the fire and rescue services.

The fire data used in this research are provided by Nanjing Fire Brigade, including 12-year (2002 - 2013) urban fire incidents for the seven districts in central Nanjing. Excluding the major events attended by more than 40 firemen, there are total 28,383 fires. Using the Census data in 2010, the population-based fire risks are calculated as the total number of fires per 1,000 population for each Jiedao (the smallest statistical geography in Chinese Census) within the study area. The results are shown in Figure 1 using the quintile classification with the background image from ArcGIS Online Map Service. It can be seen that the higher incident rates are largely located in the city center (mainly including Gulou, Xuanwu and Qinhuai) and the west of Qixia. It is not surprising as those areas have relatively higher population density and socioeconomic activities.

All the incidents have been recorded by ten categories: vehicles $(\mathrm{VH})$, non-residential buildings (NRB) (e.g. restaurants and hotels), industries (IN), retail stores (RS), refuse (RF), dwellings (DW), grassland (GL), facilities (FL) (e.g. street lights and high-tension power lines), false alarm (FA) and others (OT) (e.g. construction sites). The proportion of each fire type is depicted by Figure 2. During the study time period, almost half of the incidents are dwelling fires $(34.1 \%)$ and fires involving facilities (15.5\%). Due to limited space, the following descriptions and analyses will particularly focus on those two types of fires.

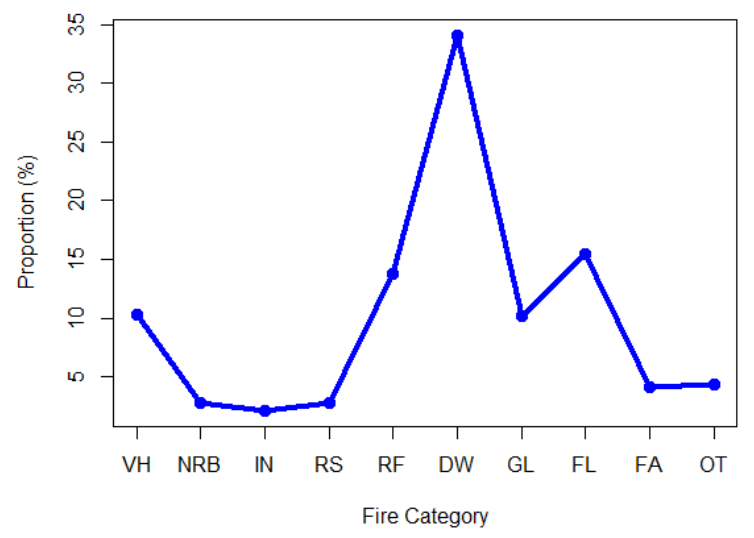

Figure 2. Proportion of different fire categories

\subsection{Spatial-temporal Analyses}

In this research, several spatial, temporal and spatial-temporal analytical methods have been employed, including both basic descriptive statistics and more advanced ESDA techniques. First, spatial distribution of fire events are explored by spatial clustering analysis. Further, temporal patterns of fires are examined using circular statistics. Finally, spatial-temporal variations of fire incidents are investigated by comaps (Brunsdon, 2001).

With regard to the spatial distribution, spatial clustering analysis is used to identify the places with significantly high concentrations of fire events, which is implemented on point and lattice data, respectively. First, using the point data representing discrete fire events, continuous surfaces of fire risks are generated by spatial KDE (Silverman, 1986), which is a spatial smoothing technique so that spatial variations of fire risks can be observed. Further, since the key small-area statistical geography in China, Jiedao, is quite large (for example, there are total 53 Jiedao within the study area and the largest one covers an area of $80.2 \mathrm{~km}^{2}$ ), the study area is discretized by a set of regular grid cells $(1.0 \mathrm{~km} * 1.0 \mathrm{~km})$ as the basic areal units. Based on the total fire events within each grid, the local clusters of high concentrations of fire incidents are identified by the local indicator of spatial association (LISA) (Anselin, 1995).

The temporal variations of fire events are examined using rose diagrams on a daily, weekly and monthly basis, respectively. Rose diagrams are graphic tools originally designed to describe wind speed and direction, but also have been adapted for describing the temporal distribution of fire events, such as the work by Corcoran et al. (2007b) and Asgary et al. (2010). In addition, the Watson's U2 test (Fisher, 1995) is employed to compare whether two circular plots representing fires of different categories have similar temporal patterns.

Finally, spatial-temporal patterns of fire incidents are explored by comap (Brunsdon, 2001). The comap visualizes the spatialtemporal processes in a 2-dimnesional manner. It is virtually a geographical extension of the coplot (Cleveland, 1993), a graphical technique examining the relationship between a pair of variables conditioned on a third variable. The distinct feature of the comap is that the pair of variables defines geographic location. For the comaps created in this research, the two dimensional spatial distribution of fire events is conditioned on the third variable - time, so the spatial-temporal variations can be observed in one visualization layout.

The above analyses are implemented with several software tools. All the statistical analyses are carried out in $\mathrm{R}$ environment (https://www.r-project.org/), an open source software framework for statistical analysis. LISA is calculated by an open source software program for spatial data analysis GeoDa (https://geodacenter.asu.edu/projects/opengeoda). Spatial data processing, manipulation and all the other spatial analyses are carried out in ArcGIS 10 (ESRI, Redlands, California).

\section{RESULTS}

\subsection{Spatial Distribution}

First, the kernel density is estimated for dwelling and facility fires. The bandwidth employed here is $1.0 \mathrm{~km}$ which is selected by trial and error in order to achieve a good visual inspection of fire distribution over geographical space. Shown in Figure 3 are the surfaces of KDE for the years 2002 and 2013, representing the start and the end of the study time period, respectively. It can be seen that for both 2002 and 2013, DW and FL fires clustered around the city center and have expanded towards the northwest of the city. Meanwhile, there is an emerging growth of incidents in the south of the study area, particularly for the DW fires.

Instead of the point data used in the KDE which represent the geographic location of fire events, the relative fire risks are employed in the LISA analyses. That is, the variable analysed is 


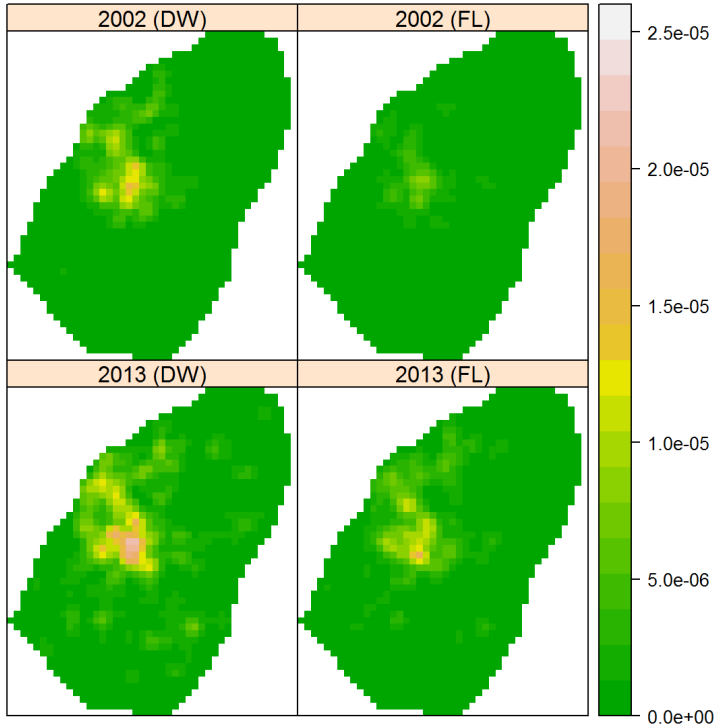

Figure 3. KDE for DW and FL fires in 2002 and 2013

defined as the proportion of a particular type of fire to all the fires. In this way, the fire of higher significance to a place can be identified and thus be emphasized in future fire prevention programs. Specifically, the study area is represented by a set of regular grid cells $(1.0 \mathrm{~km} * 1.0 \mathrm{~km})$, and the number of all fires as well as of each category is calculated for each cell. The LISA analysis results ( $\mathrm{p}$-value $<0.05$ ) for DW and FL fires (years 2002 and 2013) are presented in Figure 4, where four local clusters are defined: HH (high values surrounded by high values), LL (low values surrounded by low values), LH (low values surrounded by high values) and HL (high values surrounded by low values). It can be observed that, for the years 2002 and 2013, although both DW and FL fires are clustered around the city center as indicated by Figure 3, their contribution to the total amount of the fires at each location varies across space. For example, in 2002, both DW and FL fires mainly concentrated at the central three districts (Gulou, Xuanwu and Qinhuai) and also have relatively higher proportions compared to their contribution to that in the other places. However, in 2013, although both types of fires still largely occurred around the city center (see Figure 3), their contribution to all the fires at each location has changed. For

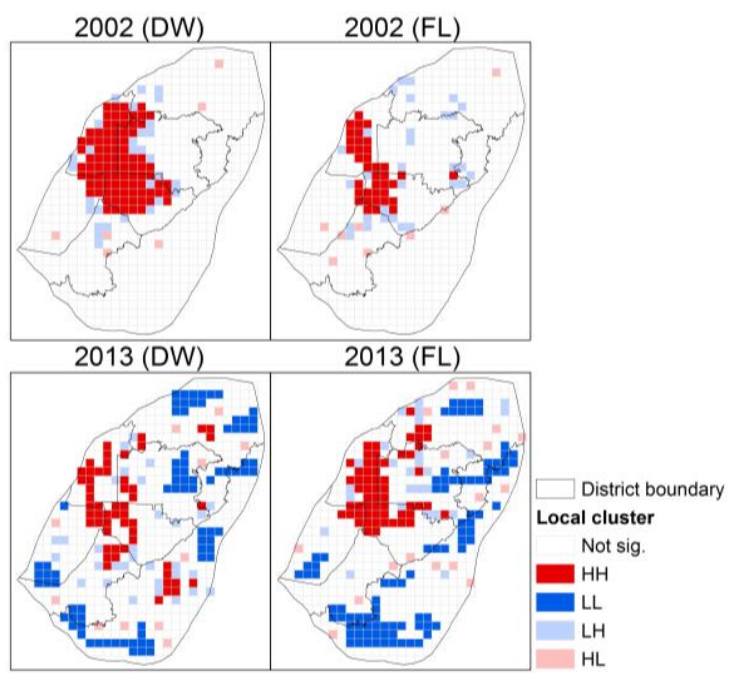

Figure 4. LISA cluster maps for DW and FL fires example, the higher risk of DW fires is emerging particularly in central Qixia and Jiangning districts. Meanwhile, the risk of DW fires has significantly decreased at part of the central areas. Regarding FL fires, while the higher risk still exists at the city center as before, it is also growing towards the east and the northeast of the study area. Finally, it is worth noting that the LL clusters of both DW and FL fires are found in 2013 but not in 2002, indicating a larger difference in their contribution to the local overall fires.

\subsection{Temporal Variations}

First, Figure 5 shows the percentage of annual variations of total, dwelling and facility fires, respectively, compared to that in year 2002. It can be seen that in general the three lines demonstrate similar temporal patterns. That is, the annual variations in fires are within 50\% until 2008 and have experienced rapid growth since then, except a slight drop in 2012 (for all types and FL) and 2011 (DW). Also, the temporal pattern of dwelling fires is more similar to that of all fires, especially during $2002-2008$ when the absolute average variation rates are about $16.8 \%$ (all types) and $15.8 \%$ (DW), while the value for FL during the same time period is about $29.5 \%$. The difference after 2008 becomes more prominent, with the absolute average variation rates are about $103.4 \%$ (all types), $68.2 \%(\mathrm{DW})$ and $136.1 \%(\mathrm{FL})$, respectively.

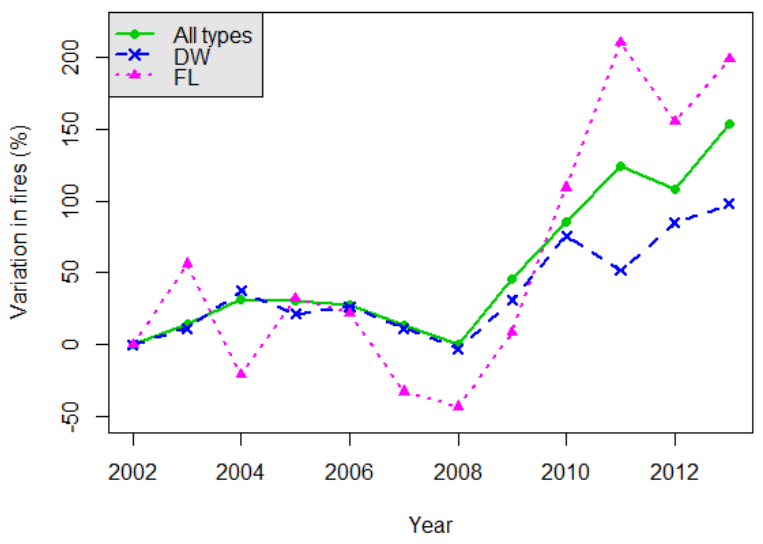

Figure 5. Annual variations of fire incidents

The temporal variations of both DW and FL fires across the study time period are further examined on a monthly, weekly and daily basis using rose diagrams. The results are shown in Figures $6-8$. In Figures 6(a), 7(a) and 8(a), the values represent the proportion of fire incidents to the overall amount of that particular type of fire. In Figures 6(b), 7(b) and 8(b), the values are calculated as the percentage of each type of fire among all the fire incidents.

In terms of monthly distribution, the highest proportions of DW and FL fires are both in July. But, there is much more variation in FL fires which has a standard deviation $2.9 \%$ (compared to $0.7 \%$ for DW fires), largely due to the higher rates in July (15.8\%) and August (12.4\%). Similar pattern also can be observed in Figure 6(b) which accounts for the contributions of DW and FL fires to all the incidents. Also, the distribution of FL fires is similar to that in Figure 6(a), with higher proportions in July and August. For DW fires, the highest proportion is in September. Overall, DW fire has higher proportions than FL fire for all the months, and on average, the monthly fire incidents contain about $34.4 \%$ of DW fires and $15.5 \%$ FL fires. 

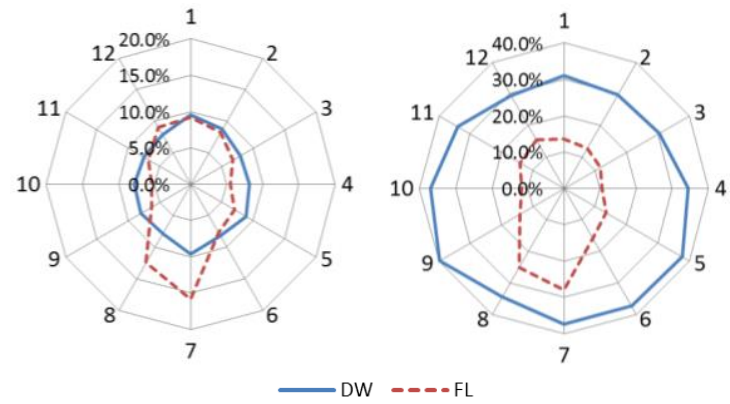

(a)

(b)

Figure 6. Monthly variations: (a) proportion to each type of fire;

(b) proportion to all fire incidents

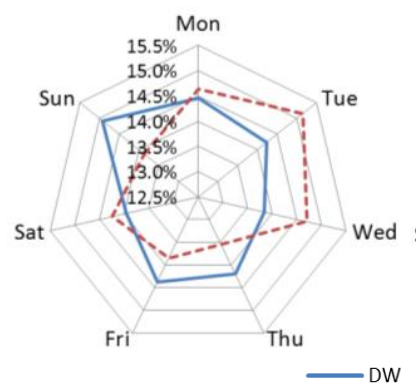

(a)

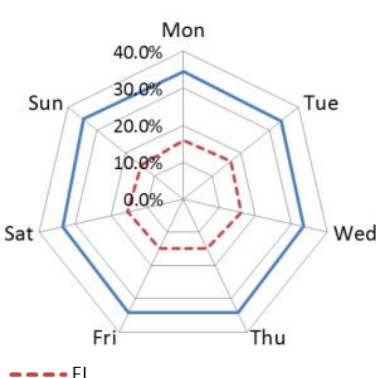

(b)
Figure 7. Weekly variations: (a) proportion to each type of fire;

(b) proportion to all fire incidents

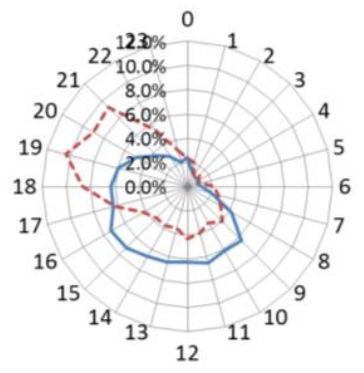

(a)

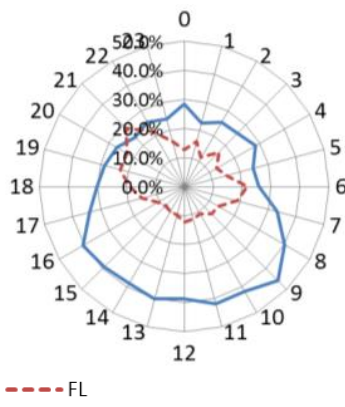

(b)
Figure 8. Daily variations: (a) proportion to each type of fire;

(b) proportion to all fire incidents

With regard to the weekly distribution, although most of the DW and FL fires occurred on Sunday (14.9\%) and Tuesday (15.1\%), respectively, the average variations in the weekly distribution for both types are relatively small, with the standard deviations about $0.3 \%$ and $0.5 \%$, respectively. The variations of contributions to all fires are a little higher, with the standard deviations about $0.5 \%$ and $0.6 \%$, but still very small compared to that of FL fires in Figure 6(b) (about 5.14\%). On average, the fires on each day of the week contain about $34.1 \%$ DW fires and $15.5 \%$ FL fires, which is similar to their proportions to monthly fires.

Compared to Figures 6 and 7, Figure 8 shows fire distribution on a finer temporal scale. Figure 8(a) indicates that most of DW fires (about $80.5 \%$ ) have occurred during $8 \mathrm{am}-9 \mathrm{pm}$. FL fires have largely occurred during 9am $-11 \mathrm{pm}$, with a total proportion about $80.0 \%$ and actually more than half $(43.6 \%)$ happened during $5 \mathrm{pm}-10 \mathrm{pm}$. In terms of their contribution to all the fires in one day, again the average hourly proportion of
DW fires is about $32.2 \%$. Particularly, the hourly rate of DW fires during $8 \mathrm{am}-5 \mathrm{pm}$ is as high as $40.6 \%$. As to FL fires, only for the time period $6 \mathrm{am}-7 \mathrm{am}$ and $7 \mathrm{pm}-11 \mathrm{pm}$, it composed more than $20 \%(21.9 \%-28.5 \%)$ of the total fires having occurred during that time.

Finally, in order to compare the monthly, weekly and hourly distribution of DW and FL fires, the Watson's U2 test is applied to the temporal variations presented in Figures 6(a), 7(a) and 8(a). The test results indicate that the temporal patterns of DW and FL fires are significantly different $(\mathrm{p}$-value $<0.05)$ from each other.

\subsection{Spatial-temporal Dynamics}

In order to generate comaps for the spatial-temporal dynamics of DW and FL fires, the incidents are grouped into several subsets that meet the rules suggested by Brunsdon (2001). That is, the adjoining subsets have certain overlap in terms of the values they cover; also, the number of fire incidents contained in each subset should be close to each other. In this way, any artificial pattern introduced by the classification processes can be avoided.

Based on the above rules, the univariate comaps for DW and FL fires by hour are shown in Figure 9. It can be seen that both DW and FL fires have largely similar spatial distribution across all the four time slots, with higher intensities of events around the city center. This is consistent with the observed pattern from Figure 3. Also, both the intensities of DW and FL fires in early afternoon (the second time slot) are a slightly lower than those of other time.

In addition, the comaps also can be created for two variables. For example, considering both weekly and daily variations, Figure 9 can be extended to bivariate comaps as shown in Figure 10. Compared to weekdays, DW fires on weekends largely clustered at the intersection of the central three districts: Gulou, Xuanwu and Qinhuai, with some incidents scattered in the surrounding areas. During the weekdays, DW fires tend to

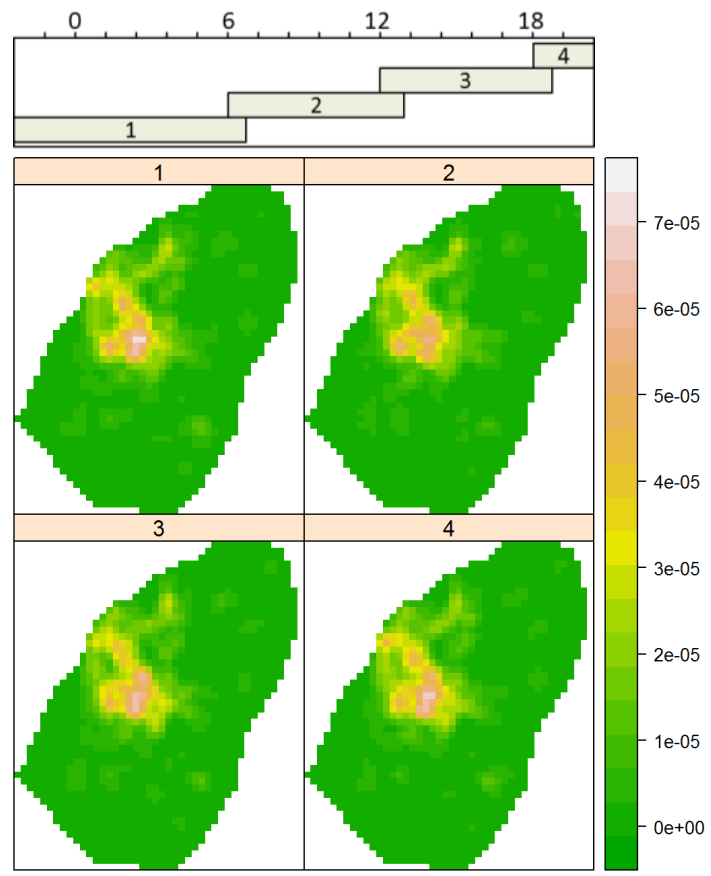

(a) 


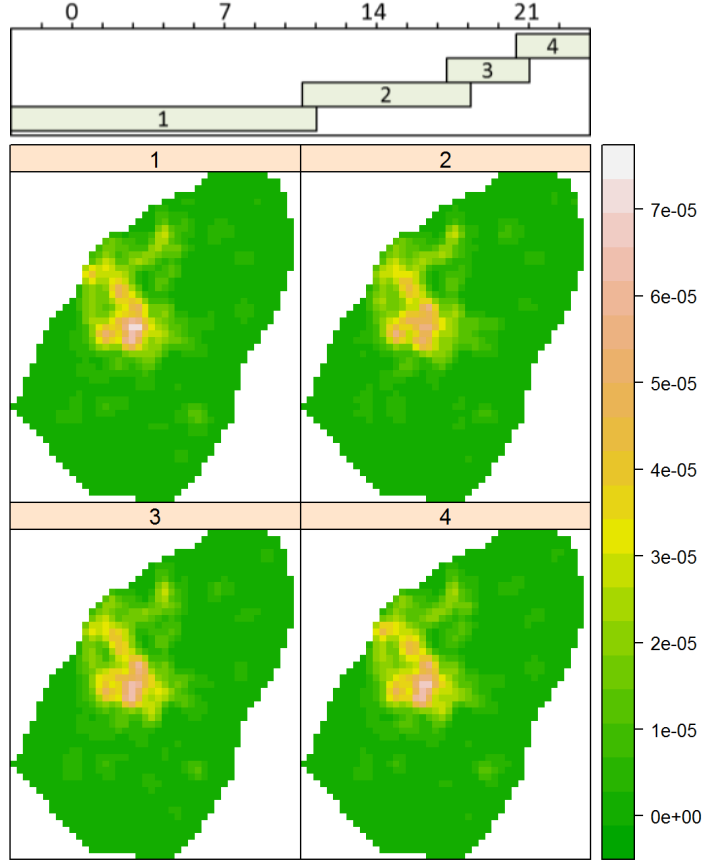

(b)

Figure 9. Univariate comaps by hour: (a) DW; (b) FL

cover more areas of those three districts, especially the area in the northwest Gulou. Again, similar patterns can be observed in Figure 10(b) for FL fires.

\section{DISCUSSION AND CONCLUSIONS}

Urban fire has long been a great threaten to properties, lives and the physical environment. Well understanding the occurrences of fire incidents can offer insights into driving factors and thereby assist decision-making for fire services and management. This research is primarily concerned with the spatial-temporal dynamics of urban fires in Nanjing, China, during 2002 - 2013. Using GIS-based spatial-temporal analysis techniques, distribution of fire events across space and time, particularly DW and FL fires, have been explored, which can help identify disadvantaged population and communities at higher fire risk.

The variations of fire incidents have been investigated from three perspectives: space, time and space-time. For the study time period, considering population distribution, Qinhuai and the intersection of Gulou, Xuanwu and Qixia have relatively higher fire rates. In terms of temporal variation, the total number of fires has grown rapidly since 2008 and in 2011 it has increased almost $200 \%$ compared to that in 2002.

As fire incidents can demonstrate different spatial-temporal characteristics due to different underlying causes, it is necessary to examine each type of incidents separately. Therefore, spatialtemporal analyses are particularly carried out for DW and FL fires which constitute about $50 \%$ of all the incidents. It is found that they have similar spatial distribution to that of all the fire events, but their contribution to all the fires at particular locations vary across time. For example, higher risks of DW fires are also found in, besides the city center, the north and south of the study area. Also, the rose diagrams suggest that for every month, each day of the week and every hour during one day, about one third fires are related to dwellings.

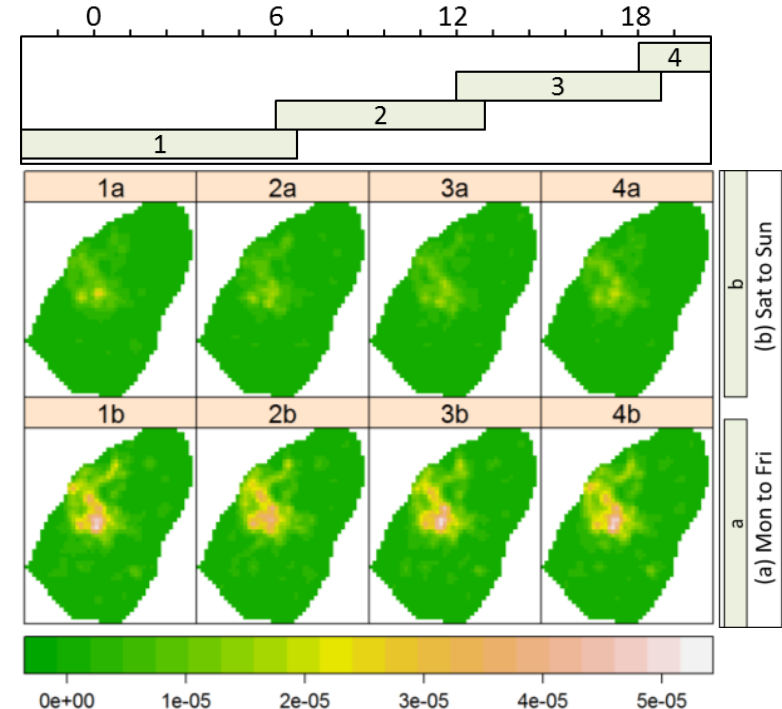

(a)

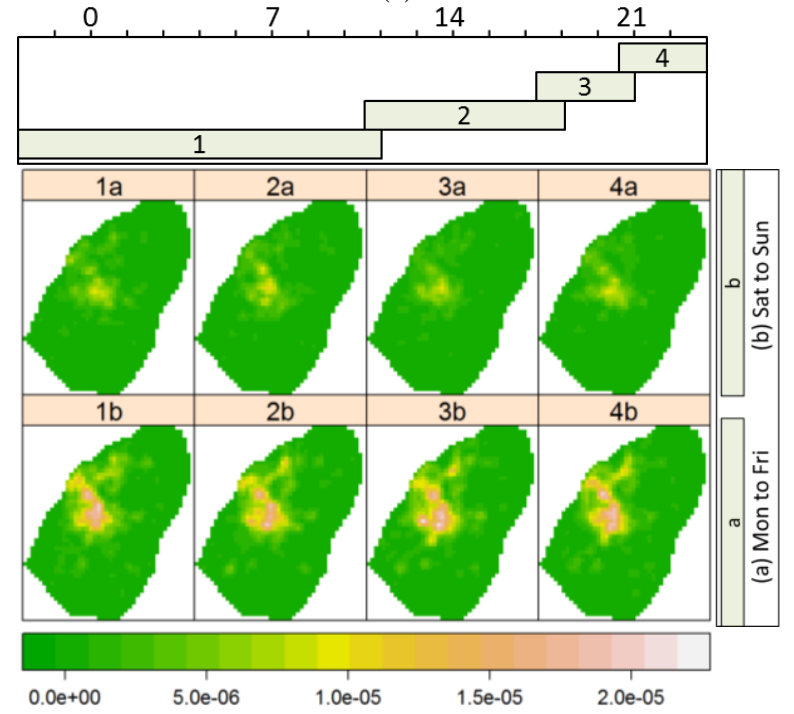

(b)

Figure 10. Bivariate comaps by week and hour: (a) DW; (b) FL

The interaction of space and time is examined by comaps. Particularly, both univariate and bivariate comps have been created for DW and FL fires. Taking hourly distribution as an example, both types of fires are found consistently clustered at the central districts for the selected time slots. When considering the weekly and hourly distribution simultaneously, it is found that the incidents in the weekdays expand towards northwest and southeast from the city center.

In addition to the above findings, this research has some limitation. For example, different definitions of subsets for the comaps might generate different results. Also, besides temporal variables, the comaps also can be extended to include other variables of interest like weather conditions and holidays.

With regard to future research, there are several areas worth further investigation. First, in addition to DW and FL fires, the other types of fires are also important to the urban safety although their proportions to all the fires are not that high. Also, based on the identified spatial-temporal patterns of urban fires, the impact of associated socioeconomic and environmental factor needs to be examined. Given the continuing urbanization 
and urban sprawl in China, it is of great importance to understand urban fire and its risks, and GIS-based spatialtemporal analyses can be powerful tools to help improve fire services and management.

\section{ACKNOWLEDGEMENTS}

This research was supported by the National Science Foundation of China (Grants 41201117).

\section{REFERENCES}

Anselin, L., 1995. Local indicators of spatial association-LISA. Geographical analysis, 27(2), 93-115.

Asgary, A., Ghaffari, A. and Levy, J., 2010. Spatial and temporal analyses of structural fire incidents and their causes: A case of Toronto, Canada. Fire Safety Journal, 45(1), pp. 44-57.

BBC News, 26 May 2015. http://www.bbc.co.uk/news/worldasia-china-32879851 (Accessed on 22 Mar, 2016).

Brunsdon, C., 2001. The comap: exploring spatial pattern via conditional distributions. Computers, environment and urban systems, 25(1), pp. 53-68.

Cleveland, W.S., 1993. Visualizing data. Hobart Press.

Corcoran, J., Higgs, G., Brunsdon, C., Ware, A. and Norman, P., 2007a. The use of spatial analytical techniques to explore patterns of fire incidence: A South Wales case study. Computers, Environment and Urban Systems, 31(6), 623-647.

Corcoran, J., Higgs, G., Brunsdon, C. and Ware, A., 2007b. The Use of Comaps to Explore the Spatial and Temporal Dynamics of Fire Incidents: A Case Study in South Wales, United Kingdom. The Professional Geographer, 59(4), 521-536.

Corcoran, J., Higgs, G. and Higginson, A., 2011a. Fire incidence in metropolitan areas: A comparative study of Brisbane (Australia) and Cardiff (United Kingdom). Applied Geography, 31(1), 65-75.

Corcoran, J., Higgs, G., Rohde, D. and Chhetri, P., 2011b. Investigating the association between weather conditions, calendar events and socio-economic patterns with trends in fire incidence: an Australian case study. Journal of Geographical Systems, 13(2), 193-226.

Cova, T. J., Dennison, P. E., Kim, T. H. and Moritz, M. A., 2005. Setting wildfire evacuation trigger points using fire spread modeling and GIS. Transactions in GIS, 9(4), 603-617.

Department for Communities and Local Government (DCLG), 2015. Fire Statistics: Great Britain April 2013 to March 2014. https://www.gov.uk/government/uploads/system/uploads/attach ment_data/file/410287/Fire_Statistics_Great_Britain_201314__PDF_Version_.pdf (Accessed on 22 Mar. 2016).

Deng, X., Huang, J., Rozelle, S. and Uchida, E., 2008. Growth, population and industrialization, and urban land expansion of China. Journal of Urban Economics, 63(1), 96-115.

Fisher, N.I., 1995. Statistical analysis of circular data. Cambridge University Press, Cambridge, UK.
Gaither, C. J., Poudyal, N. C., Goodrick, S., Bowker, J. M., Malone, S. and Gan, J., 2011. Wildland fire risk and social vulnerability in the Southeastern United States: An exploratory spatial data analysis approach. Forest Policy and Economics, 13(1), 24-36.

Higgins, E., Taylor, M., Jones, M. and Lisboa, P. J. G., 2013. Understanding community fire risk-A spatial model for targeting fire prevention activities. Fire Safety Journal, 62, 2029.

Jennings, C. R., 2013. Social and economic characteristics as determinants of residential fire risk in urban neighborhoods: A review of the literature. Fire Safety Journal, 62, 13-19.

Kalabokidis, K., Athanasis, N., Gagliardi, F., Karayiannis, F., Palaiologou, P., Parastatidis, S. and Vasilakos, C., 2013. Virtual Fire: A web-based GIS platform for forest fire control. Ecological informatics, 16, pp. 62-69.

Karter, Jr. M. J., 2014. Fire loss in the United States During 2013.

http://tkolb.net/FireReports/2014/FireCausesByMonthGraph.pd $\mathrm{f}$ (Accessed on 22 Mar, 2016)

National Bureau of Statistics of China (NBSC), 2015. China Statistical Yearbook - 2015. China Statistics Press (in Chinese). Beijing, China.

National Bureau of Statistics of China (NBSC), 2011. Tabulation on the 2010 Population Census of the People's Republic Of China. China Statistics Press (in Chinese). Beijing, China.

Ren, X., 2013. Urban China. Polity Press, Cambridge, UK.

Silverman, B. W., 1986. Density estimation for statistics and data analysis. Chapman and Hall, London, UK.

Špatenková, O. and Virrantaus, K., 2013. Discovering spatiotemporal relationships in the distribution of building fires. Fire Safety Journal, 62, pp.49-63.

Xinhua News, 2010. http://news.xinhuanet.com/politics/201011/17/c_12787131.htm (Accessed on 23 Mar, 2016) (in Chinese).

Yassemi, S., Dragićević, S. and Schmidt, M., 2008. Design and implementation of an integrated GIS-based cellular automata model to characterize forest fire behaviour. Ecological Modelling, 210(1), 71-84. 